\title{
Análise da sobrevivência de implantes dentários osseointegraveis realizados na Área de Cirurgia Buco-Maxilo-Facial da FOP-Unicamp e instalados em região posterior de maxila reconstruídas pela técnica de sinus lift.
}

\author{
Alexander Tadeu Sverzut (PQ), Beatriz Torriani de Almeida (IC).
}

\begin{abstract}
Resumo
Reabilitações na região posterior da maxila são geralmente confrontadas com atrofia óssea, associada à pneumatização do seio maxilar, impedindo a instalação de implantes de comprimento adequado. A finalidade deste estudo retrospectivo está sendo investigar o índice de sobrevivência de implantes dentários osseointegraveis instalados em áreas em que foram realizadas cirurgias de elevação de assoalho de seio maxilar na Área de Cirurgia Buco-Maxilo-Facial da Faculdade de Odontologia de Piracicaba - FOP/Unicamp no período de 2002 a 2012.
\end{abstract}

Palavras chave: Implantes, osseointegravéis, maxila.

\section{Introdução}

A perda dentária exerce historicamente uma influência marcante na vida do homem. Na contemporaneidade, a Odontologia inquieta-se em reestabelecer morfologia, função, estética, comodidade e saúde ao sistema estomatognático (Tatum, 1986). De fato, desde o advento da osseointegração, descoberta por Brånemark et al., em 1969 - e estudada exaustivamente por diversos autores desde então, pode-se oferecer uma solução segura e bastante previsível para as ausências dentárias (Brånemark et al., 1977). No entanto, a instalação de implantes na região posterior da maxila é várias vezes confrontada com processos alveolares reabsorvidos, resultantes de uma combinação da pneumatização do seio maxilar, doença periodontal, reabsorção óssea fisiológica que sucede as exodontias. Desta forma, foi delineado um estudo retrospectivo para realizar uma análise da sobrevivência de implantes dentários instalados em áreas em que foram realizadas EASM pela Área de Cirurgia e Traumatologia Buco-Maxilo-Faciais no período de 2002 a 2012.

\section{Resultados e Discussão}

Dos $3037(100 \%)$ prontuários analisados, somente $84(2,76 \%)$ prontuários foram selecionados para a pesquisa. De toda a amostra analisada em apenas 3 pacientes ocorreu a perda precoce de implantes. Em 1 paciente ocorreu a perda de 2 implantes no momento da reabertura para colocação do cicatrizador por mobilidade do mesmo. Em 1 paciente ocorreu a perda de 1 implante por mobilidade do mesmo, antes da cirurgia de reabertura para colocação do cicatrizador. Em outro paciente, ocorreu a perda do implante no dia de sua colocação por fratura da parede óssea vestibular. De toda amostra 3 pacientes tiveram insucesso no tratamento antes da colocação do implante. Em 1 paciente, que iria colocar implante na região do dente 27 , houve exposição do enxerto na crista alveolar e o paciente foi encaminhado para reabilitação com prótese parcial removível. No segundo paciente, ocorreu perfuração de membrana no trans operatório do procedimento Sinus Lift, que gerou o cancelamento da reabilitação com implante na região do dente 14 . Por fim, o último paciente teve deiscência de enxerto no pós operatório da cirurgia de Sinus Lift acarretando na abortagem do procedimento de reabilitação com implante na região do dente 26 .

\section{Conclusões}

Logo, até o perante momento da pesquisa verificou-se que a sobrevida dos implantes é alta, já que de 84 pacientes apenas 6 pacientes perderam os implantes em alguma fase do tratamento.

\section{Agradecimentos}

Agradeço ao Prof. Dr. Alexander Tadeu Sverzut, pela dedicação e paciência. $E$ a instituição FAPESP.

\footnotetext{
Brånemark PI, Hansson $\mathrm{BO}$, Adell R, Breine U, Lindstrom J, Hallen O, Ohman A. Osseointegrated implants in the treatment of the edentulous jaw. Experience from a 10-year period. Scand $J$ Plast Reconstr Surg Suppl. 1977; 16: 1-132.

${ }^{2}$ Tatum H Jr. Maxillary and sinus implant reconstructions. Dent Clin North Am. 1986 Apr;30(2):207-29.
} 